\title{
The mapping and investigation of radionuclide pollution in the processing plant of a spent phosphate mine by using GIS techniques
}

\author{
Jacques Bezuidenhout ${ }^{1}$ \\ ${ }^{1}$ Faculty of Military Science, Stellenbosch University, South Africa, jab@ma2.sun.ac.za
}

\section{DOI: $\underline{\text { http://dx.doi.org/10.4314/sajg.v7i3.11 }}$}

\begin{abstract}
The mining and refinement of phosphate is characterised by high levels of uranium. An in situ gamma ray survey was done at the processing plant of a spent phosphate mine near Vredenburg on the west coast of South Africa in order to assess radionuclide concentrations. The concentrations of potassium, thorium and radioactive progeny of uranium were measured and plotted with the help of QGIS software. The results demonstrated high concentrations in specific areas of the plant. The highest concentrations were found to be $898 \mathrm{~Bq} / \mathrm{kg}$ for potassium, $162 \mathrm{~Bq} / \mathrm{kg}$ for ${ }^{232} \mathrm{Th}$ and 639 $\mathrm{Bq} / \mathrm{kg}$ for ${ }^{226} \mathrm{Ra}$. It was demonstrated that the refinement process technologically enhanced the naturally occurring radioactive nuclides and contaminated sections of the processing plant. The causes of the contamination were also investigated. The effective dose for the various parts of the processing plant was also estimated and the highest level was found to be $0.45 \mathrm{mSv} / \mathrm{y}$. The article finally draws conclusions as to the environmental impact of the radiation and possible future preventative measures that could be followed in order to minimize pollution.
\end{abstract}

Keywords: Environmental pollution, GIS techniques, Gamma ray measurements, uranium, phosphate mining.

\section{Introduction}

High levels of uranium are typically associated with the phosphate industry and the mining of phosphate deposits. The uranium concentrations are even higher when the phosphate deposits are of marine origin [1,2]. Such high levels of radioactive uranium can have a significant impact on humans and the natural environment, specifically when concentrations are further enhanced through industrial processes like refinement $[3,4]$.

Marine phosphate deposits were mined from 1943 to 1993 at a site near Vredenburg on the west coast of South Africa (Figure 1). The phosphate deposits were formed in a river delta that dates back to the late Miocene and early Pliocene epochs [5]. Numerous fossils were unearthed during the mining operation and the subsequent closing of the mine presented itself as an ideal opportunity for the establishment of a fossil park. The West Coast Fossil Park was consequently founded on 22 September 1998 and several paleontological and environmental projects were initiated. The old mine office block were renovated and transformed into a popular visitors area. A new and modern 
visitor's centre, much closer to the current fossil excavations, is also currently under construction [6].

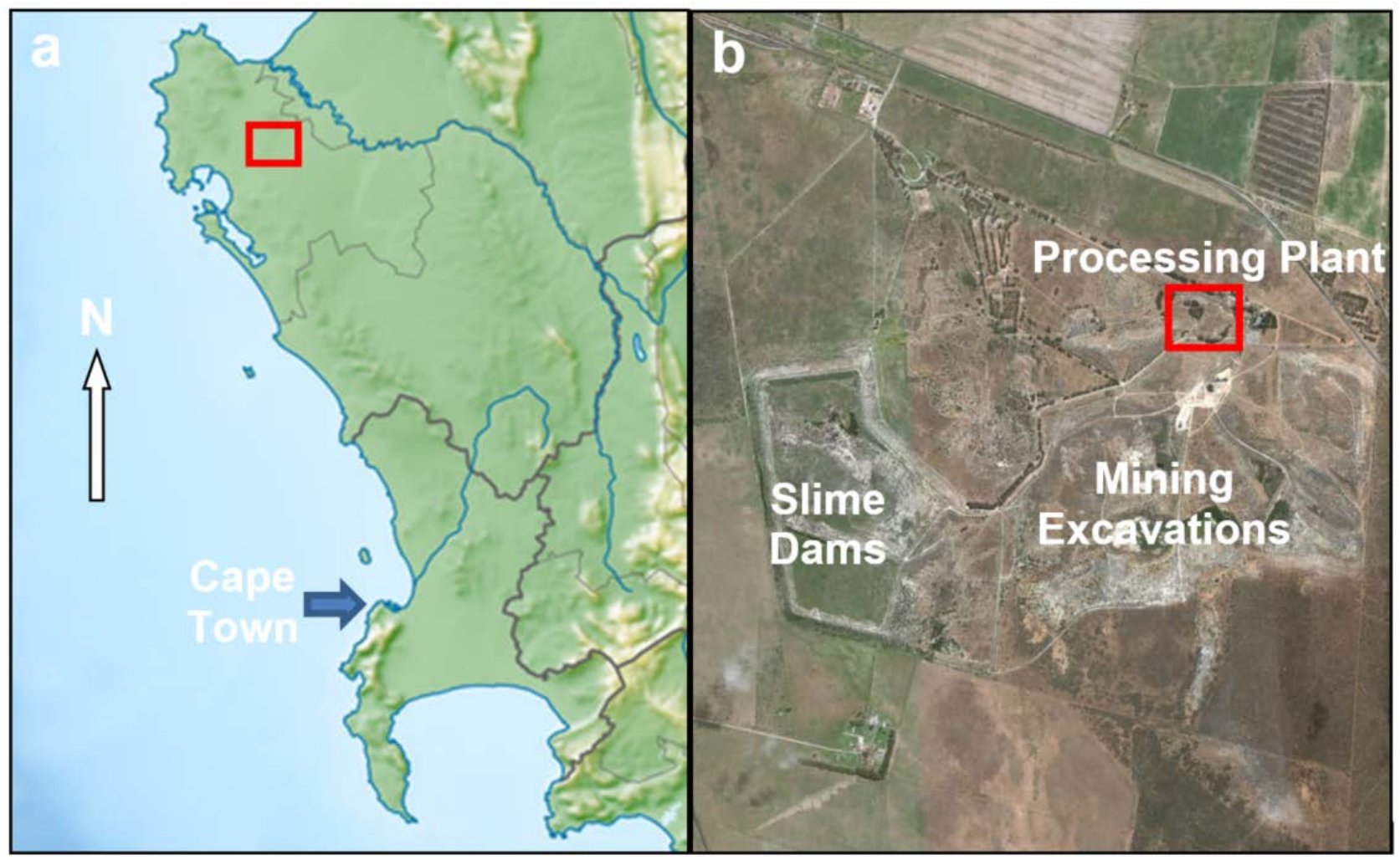

Figure 1. A map of the west coast of South Africa (a) indicating the position of the spent phosphate mine and a Google Earth image of the mine (b) indicating the different sections of the mine.

An exploratory survey of the West Coast Fossil Park was conducted during January 2015 and elevated levels of the radioactive progeny of uranium were found at three distinct areas of the old mine, namely the slime dams, the mine excavations and the processing plant [7]. The highest levels were found at the processing plant and this raised concerns. A dedicated study of the processing plant was proposed in order to accurately determine the extent of the radioactive contamination and the associated environmental and exposure risk. An intensive radionuclide survey was therefore undertaken during 2016 in order to estimate the prevalence of residual nuclides at the processing plant of the spent mine. The following sections deal with the methods, analyses, results and conclusions of this study. Possible future actions that could be followed to prevent risks that are associated with these nuclides are also investigated.

\section{Method}

The main naturally occurring nuclides are uranium $\left({ }^{238} \mathrm{U}\right)$, thorium $\left({ }^{232} \mathrm{Th}\right)$ and potassium $\left({ }^{40} \mathrm{~K}\right)$ of which potassium is the most abundant. These nuclides are all of primordial origin and their concentrations relate well to their geographical features. Uranium and thorium decay through long decay chains before reaching stable isotopes. The most prominent daughter in the decay chain of 
uranium is the long-lived radium $\left({ }^{226} \mathrm{Ra}\right)$ nuclide. The secular equilibrium between uranium and radium are usually disturbed when undergoing processing. This work will therefore refer to radium rather than uranium. The study will consequently investigate variations in potassium, thorium and radium concentrations, keeping in mind the close relationship between radium and uranium.

\subsection{Measuring System}

The Gamma In Situ Portable Instrument (GISPI) was used to radio survey the processing plant of the spent phosphate mine. The GISPI consists of a NaI(Tl) scintillation detector, a digital Multi Channel Analyser (MCA), a rugged tablet PC with an on-board GPS and real-time analyses software that controls the whole system [8]. The $\mathrm{NaI}(\mathrm{Tl})$ detector $(7.62 \times 7.62 \mathrm{~cm})$ is coupled to the MCA and sealed in a padded case to protect the instruments from mechanical shock and dust. The scintiSPEC ${ }_{\circledast}$ MCA that is produced by FLIR $\circledast$ has a USB connection that acts as the power source for operation and allows data transfer [9]. A Trimble ${ }_{\circledast}$ Yuma rugged tablet PC with on-board GPS manages the systems [10]. The detector system was mounted on a quad motorcycle with the detector fitted to the front metal structure of the motorcycle, $20 \mathrm{~cm}$ from the ground. The Yuma rugged tablet PC was mounted on the front carrier (Figure 2).

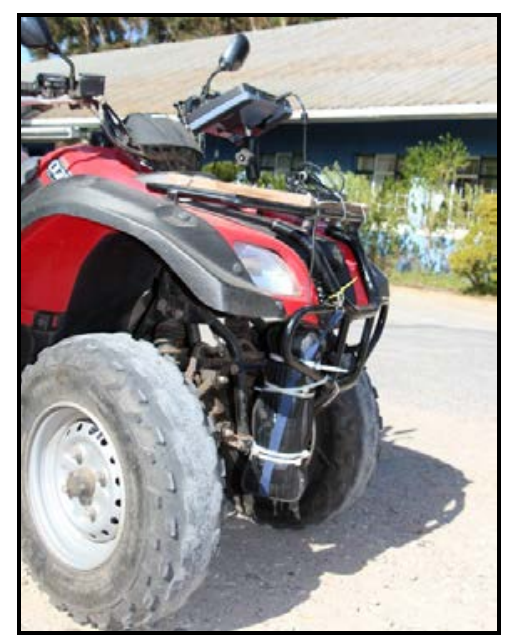

Figure 2. Photograph of the measuring system that was utilised during the in situ measurements. The photograph shows the casing with the detector mounted to the frame and the tablet with an onboard GPS on the carrier.

The GISPI controls the system settings and spectrum acquisition by means of winTMCA32® software with 1024 channels. The winTMCA32 ${ }_{\circledast}$ code also acquired the geographical position coordinates from the on-board GPS on the Yuma tablet. The code stored all hardware settings, in situ spectra and the extracted results in files. The result files were finally read into and interpreted by the QGIS software. 


\subsection{Calibrations}

Energy calibration was done between 0.2 to $2.7 \mathrm{MeV}$ by using caesium $\left({ }^{137} \mathrm{Cs}\right)$, cobalt $\left({ }^{60} \mathrm{Co}\right)$ and natural environmental spectra. The symmetry assumptions and corrections described by McCay et al. [11] were adopted for the calibrations and surveys.

The efficiency calibration were done by selecting $1460.8 \mathrm{keV}, 1764.5 \mathrm{keV}$ and $2614.5 \mathrm{keV}$ as energy counting windows and these are denoted by $i$ equal to 1,2 , and 3 , respectively. The calibration standards of potassium, uranium and thorium were specified by $j$ and equal to 1,2 and 3 , respectively. The count rate $R_{i, j}$ in the $i$ th window of a calibration standard $j$ is then proportional to the nuclide activity $A_{n, j}$ denoted by $n$. The count rate can be expressed as

$$
R_{i, j}=\sum_{n=1}^{3} e_{i, n} A_{n, j}
$$

where $e_{i, n}$ give the counting efficiency in the ith window for the nuclide $n$, and with $n=1,2$ and 3 representing the ${ }^{40} \mathrm{~K},{ }^{226} \mathrm{Ra}$ and ${ }^{232} \mathrm{Th}$ nuclides. The count rate in each window is

$$
R_{i, j}=\frac{N_{i, j}}{t_{j}}
$$

where $N_{i, j}$ is the counts in the $i$ th window for calibration standard $j$, and $t_{j}$, is the counting time for standard $j$.

Eq. (1) represents a linear system of $i \times n$ (3 x 3) simultaneous equations. The counting efficiencies can then be solved by relating the count rates of the windows in the calibration standard spectra with the known nuclide concentration in each standard.

The contribution of ${ }^{40} \mathrm{~K}$ in the ${ }^{226} \mathrm{Ra}$ and ${ }^{232} \mathrm{Th}$ windows were neglected which is similar to assumptions that were made by Rybach [12,13]. It was further assumed that the influence of ${ }^{226} \mathrm{Ra}$ on the ${ }^{232}$ Th window could also be neglected for the same reason. By applying the content characteristics of the standard spectra the calculations could be simplified. The twelve counting efficiencies were then reduced to six. The count rates in the ${ }^{40} \mathrm{~K}$ window for the potassium, uranium and thorium standards were then given by

$$
\begin{aligned}
& R_{1,1}=e_{1,1} A_{1,1}+e_{1,2} A_{2,1}+e_{1,3} A_{3,1} \\
& R_{1,2}=e_{1,1} A_{1,2}+e_{1,2} A_{2,2}+e_{1,3} A_{3,2} \\
& R_{1,3}=e_{1,1} A_{1,3}+e_{1,2} A_{2,3}+e_{1,3} A_{3,3}
\end{aligned}
$$

The count rates in the ${ }^{226} \mathrm{Ra}$ window for the uranium and thorium standard were then

$$
\begin{aligned}
& R_{2,2}=e_{2,2} A_{2,2}+e_{2,3} A_{3,2} \\
& R_{2,3}=e_{2,2} A_{2,3}+e_{2,3} A_{3,3}
\end{aligned}
$$

The count rate in the ${ }^{232} \mathrm{Th}$ window for the thorium standard was

$$
R_{3,3}=e_{3,3} A_{3,3}
$$


The solutions for the efficiencies were as follows:

$$
\begin{aligned}
e_{1,1} & =\frac{R_{1,1}}{A_{1,1}} \\
e_{1,2} & =\frac{R_{1,3} A_{3,2}-R_{1,2} A_{3,3}}{A_{2,3} A_{3,2}-A_{2,2} A_{3,3}} \\
e_{1,3} & =\frac{R_{1,2}}{A_{3,2}}-\frac{A_{2,2}}{A_{3,2}}\left[\frac{R_{1,3} A_{3,2}-R_{1,2} A_{3,3}}{A_{2,3} A_{3,2}-A_{2,2} A_{3,3}}\right] \\
e_{2,2} & =\frac{R_{2,3} A_{3,2}-R_{2,2} A_{3,3}}{A_{2,3} A_{3,2}-A_{2,2} A_{3,3}} \\
e_{2,3} & =\frac{R_{2,2}}{A_{3,2}}-\frac{A_{2,2}}{A_{3,2}}\left[\frac{R_{2,3} A_{3,2}-R_{2,2} A_{3,3}}{A_{2,3} A_{3,2}-A_{2,2} A_{3,3}}\right] \\
e_{3,3} & =\frac{R_{3,3}}{A_{3,3}}
\end{aligned}
$$

Equation (1) can be used in association with the counting efficiencies to obtain the activity $A_{K}$ (for the $1460.8 \mathrm{keV}$ window), $A_{R a}$ (for the $1764.5 \mathrm{keV}$ window) and $A_{\text {Th }}$ (for the $2614.5 \mathrm{keV}$ window) related to ${ }^{40} \mathrm{~K},{ }^{226} \mathrm{Ra}$ and ${ }^{232} \mathrm{Th}$, respectively. The activities for each in situ measurement were then extracted from the net count rates $R_{K}, R_{R a}$ and $R_{T h}$ that were measured in the three windows. Hence, $A_{K}, A_{R a}$ and $A_{T h}$ were obtained by solving the following set of simultaneous equations.

$$
\begin{aligned}
& R_{K}=e_{1,1} A_{K}+e_{1,2} A_{R a}+e_{1,3} A_{T h} \\
& R_{U}=e_{2,2} A_{R a}+e_{2,3} A_{T h} \\
& R_{T h}=e_{3,3} A_{T h}
\end{aligned}
$$

The effective dose rates were then estimated by means of the method described by Agbalagba et al. [14]. The absorbed dose rate $(D)$ was calculated in $\mathrm{nGy/h}$ by

$$
D=\left(0.621 A_{K}+0.462 A_{R a}+0.0417 A_{T h}\right) .
$$

The effective dose rate ( $\left.E_{f f} D o s e\right)$ was then calculated in mSv/y by

$$
E_{f f} \text { Dose }=\left(1.23 \times 10^{-3} \times D\right) \text {. }
$$

\subsection{Measurements and analyses}

The efficiency calibrations measurements of the system were done at standard radiation reference pads of the Nuclear Energy Corporation of South African (NECSA) according to the method described by Chiozzi and others $[15,16]$ and all the nuclide concentrations were calculated and expressed in Becquerel per kilogram.

The ${ }^{40} \mathrm{~K}$ nuclide that emits a single gamma ray of $1460 \mathrm{keV}$ consists of $0.0117 \%$ of the weight of naturally occurring potassium [17]. Potassium is relatively abundant in nature and the ${ }^{40} \mathrm{~K}$ emission is subsequently very strong in a natural spectra. The $1460 \mathrm{keV}$ emission of ${ }^{40} \mathrm{~K}$ was therefore 
chosen as centroid for an active stabilisation function. This stabilisation function which is part of the winTMCA32 software was used to correct for energy drift.

The activity concentrations of ${ }^{226} \mathrm{Ra},{ }^{232} \mathrm{Th}$ and the effective dose rate of the various sample points were plotted and interpolated with QGIS software and overlaid on Google Earth images of the mine. The images are illustrated in Figures 3, 5, 8 and 10. Thiessen polygons of the measured concentrations were also generated and overlaid on photographs of a scale model of the old mine. This is illustrated in Figure 4.

\section{Results and Discussion}

The measuring system was mounted on a quad motorcycle (Figure 2) during this survey and in situ measurements were taken only in and around the processing plant of the old mine. An area of $0.2 \mathrm{~km}^{2}$ was covered over a period of two days. The extracted radium concentrations of the survey in the processing plant are plotted in Figure 3. There are substantial variations in the radium concentrations in the processing plant. The highest levels are mainly confined to the central part of the plant, but elevated levels are also evident in some other sectors of the plant. A soil sample was taken in the centre of the plant at a depth of $30 \mathrm{~cm}$ and then analysed in a conventional laboratory measurement. Concentrations of $300.9 \mathrm{~Bq} / \mathrm{kg}$ and $48.1 \mathrm{~Bq} / \mathrm{kg}$ were found for radium and thorium, respectively. These concentrations are in agreement with the in situ measurements that were conducted in study area.

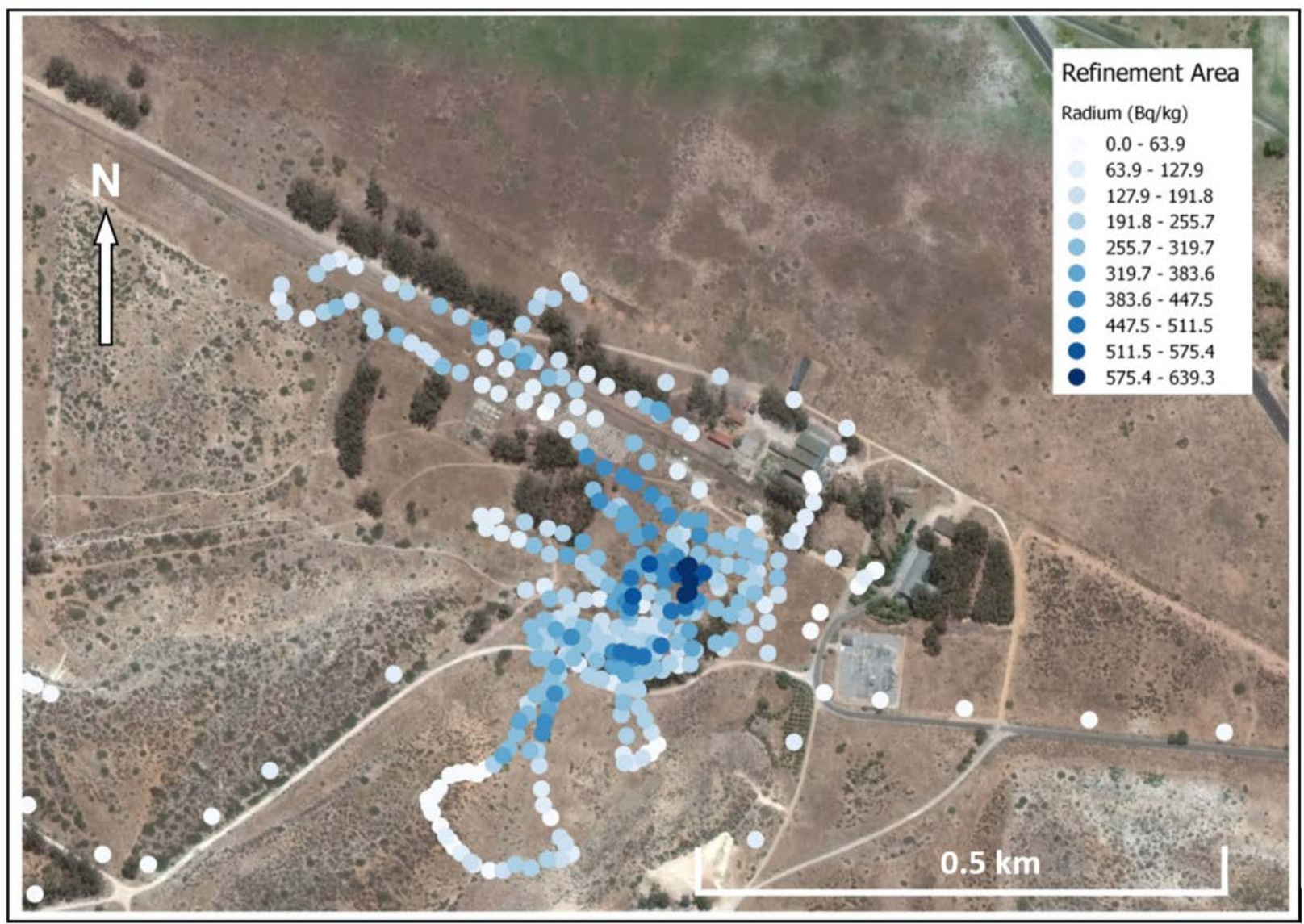

Figure 3. A Google Earth image with a colour-graded overlay indicating the radium concentrations in the processing plant area of the spent phosphate mine. 
Most of the structures in the processing plant were demolished after the closure of the mine. Currently there are only a few small buildings left on the site while some of the floor surfaces of the larger buildings are still visible. Therefore, a scale model dating from the mining operation that displays all the structures in the processing plant were utilized in the study. A photograph of the scale model was georeferenced and Thiessen polygons of the radium concentration data were overlaid. Figure 4(a) displays the photograph of the scale model of the processing plant and Figure 4(b) shows the model with the Thiessen polygon overlay. It is evident that high radium levels are prevalent in the areas where the milling and phosphate storage took place. The open storage area between the mills and the supply store coincides with the highest level of radium with concentrations being in excess of $600 \mathrm{~Bq} / \mathrm{kg}$. A corridor of elevated radium concentrations that runs from the storage area to the loading facility at the railroad tracks is also evident. The highest radium contaminations are thus associated with the final stages of the phosphate refinement.

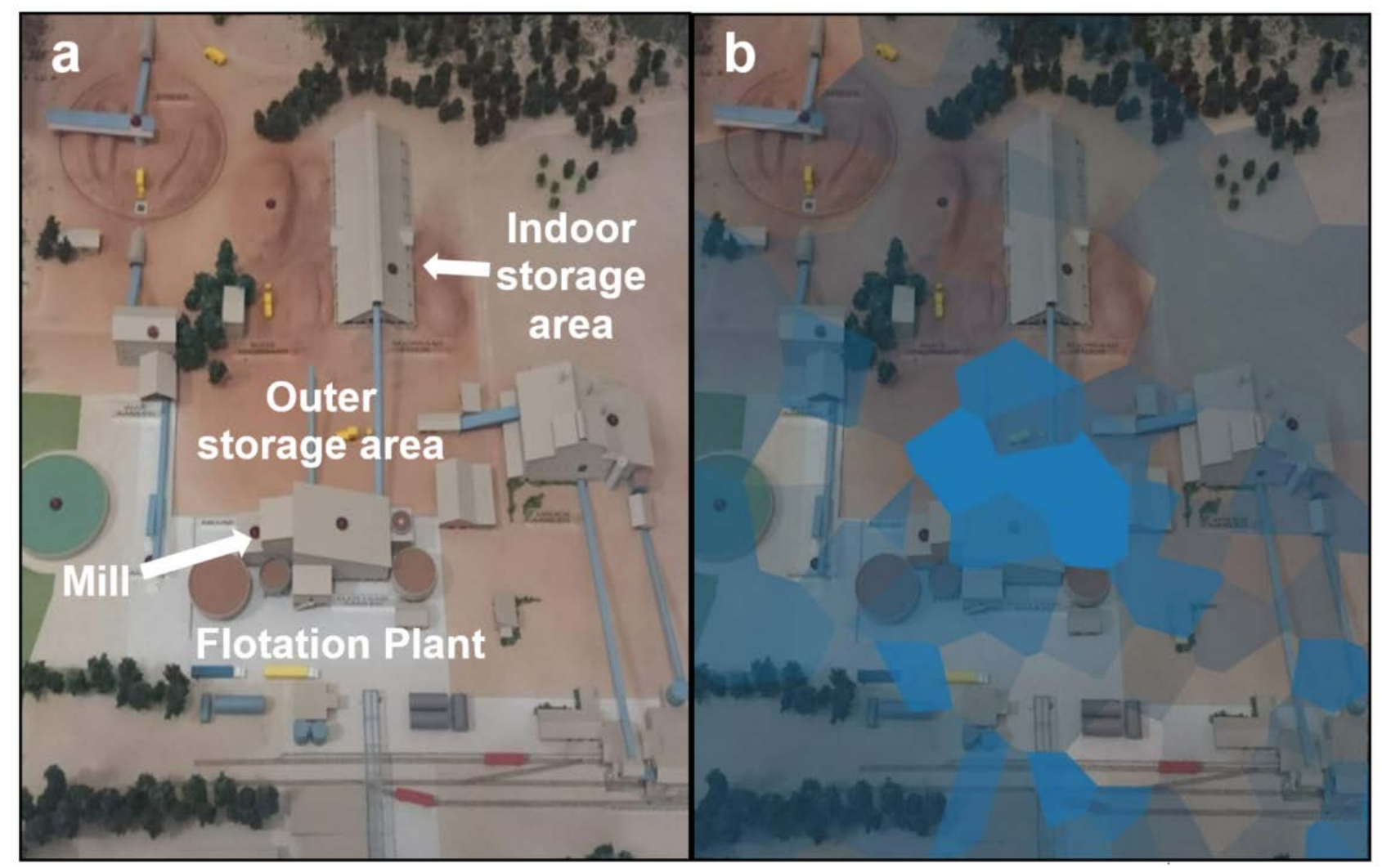

Figure 4. An image of a scale model of the processing plant which indicates the prominent structures illustrated on the left (a). Thiessen polygons of the radium concentrations are overlaid on the image of the scale model and this is illustrated on the right (b).

Refinement of ore is typically accompanied by an increase in radionuclide concentrations and this is referred to as technologically enhanced naturally occurring radioactive material [18]. The high concentrations of radium in the processing plant indicate that spillages of enhanced radium concentrations contaminated the soil of the areas where the final phosphate refinement and storage occurred. Radium may also have leaked from the stored phosphate, resulting in radioactive 
contamination of the mentioned areas. The high radium levels in the corridors to the railroad track indicate that spillage of radium also occurred while the phosphate were transported and loaded. The radium levels on the concrete surfaces of the original building were low which indicate that spillages or residue at these areas were easily cleaned. It is therefore evident that enhanced radium concentrations penetrated the soil in areas where no concrete layer or floor cover was present. This made effective removal of residual radionuclides very difficult during the decommissioning of the mine.

The relationship between radium (uranium) and thorium concentrations is well known with natural concentrations of thorium generally higher than that of radium $[19,20]$. The thorium concentrations in Figure 5 demonstrate fairly similar variations to that of the radium concentrations in Figure 3, but the highest levels of the two nuclides do not coincide. The overall highest thorium concentration was $162 \mathrm{~Bq} / \mathrm{kg}$, but this sampling point revealed a lower radium concentration of 114 $\mathrm{Bq} / \mathrm{kg}$. The thorium concentrations decrease as the distance from the central part of the plant increases and this is demonstrated in Figure 6.

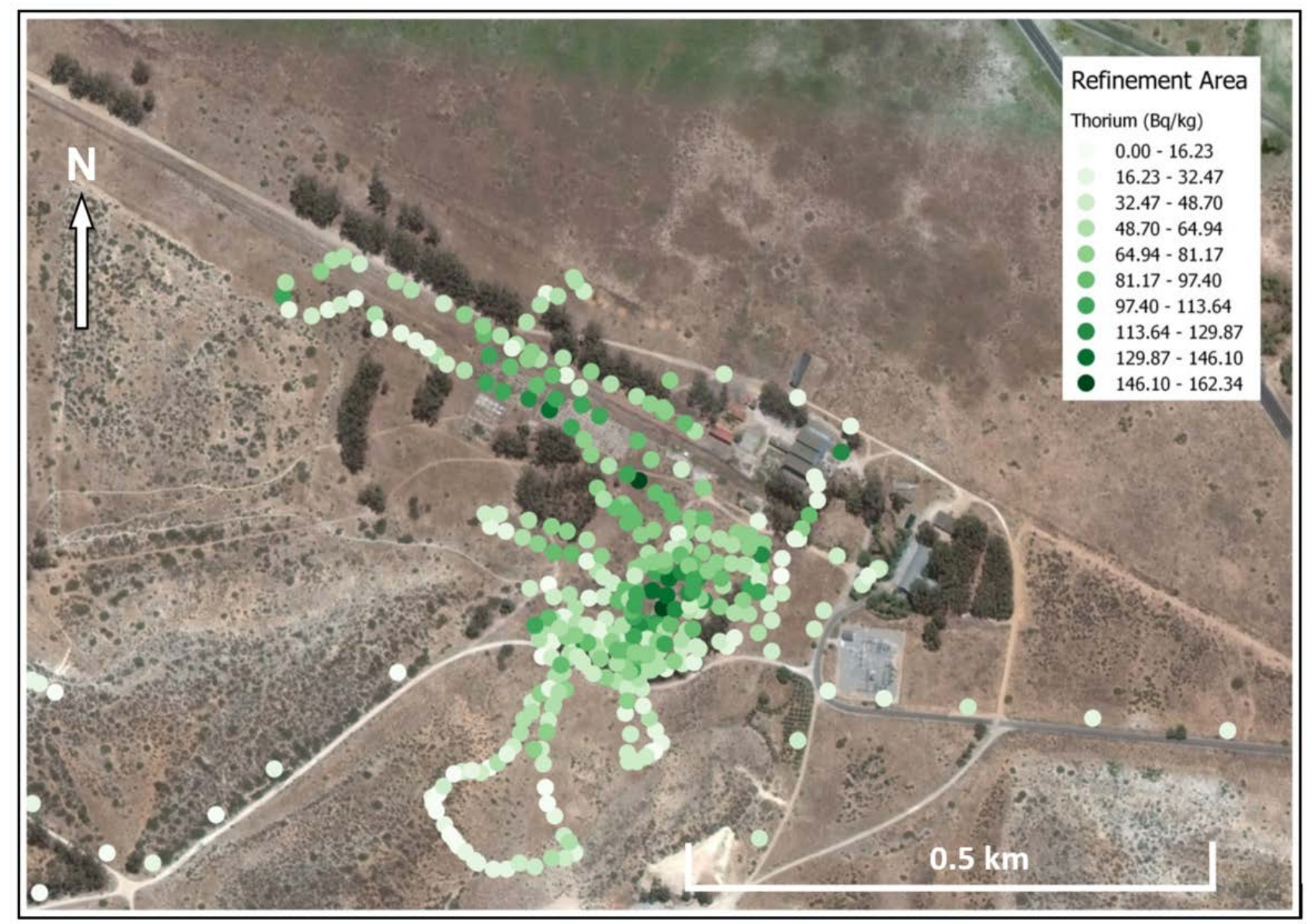

Figure 5. A Google Earth image with a colour-graded overlay indicating the thorium concentrations in the area of the spent phosphate mine. 


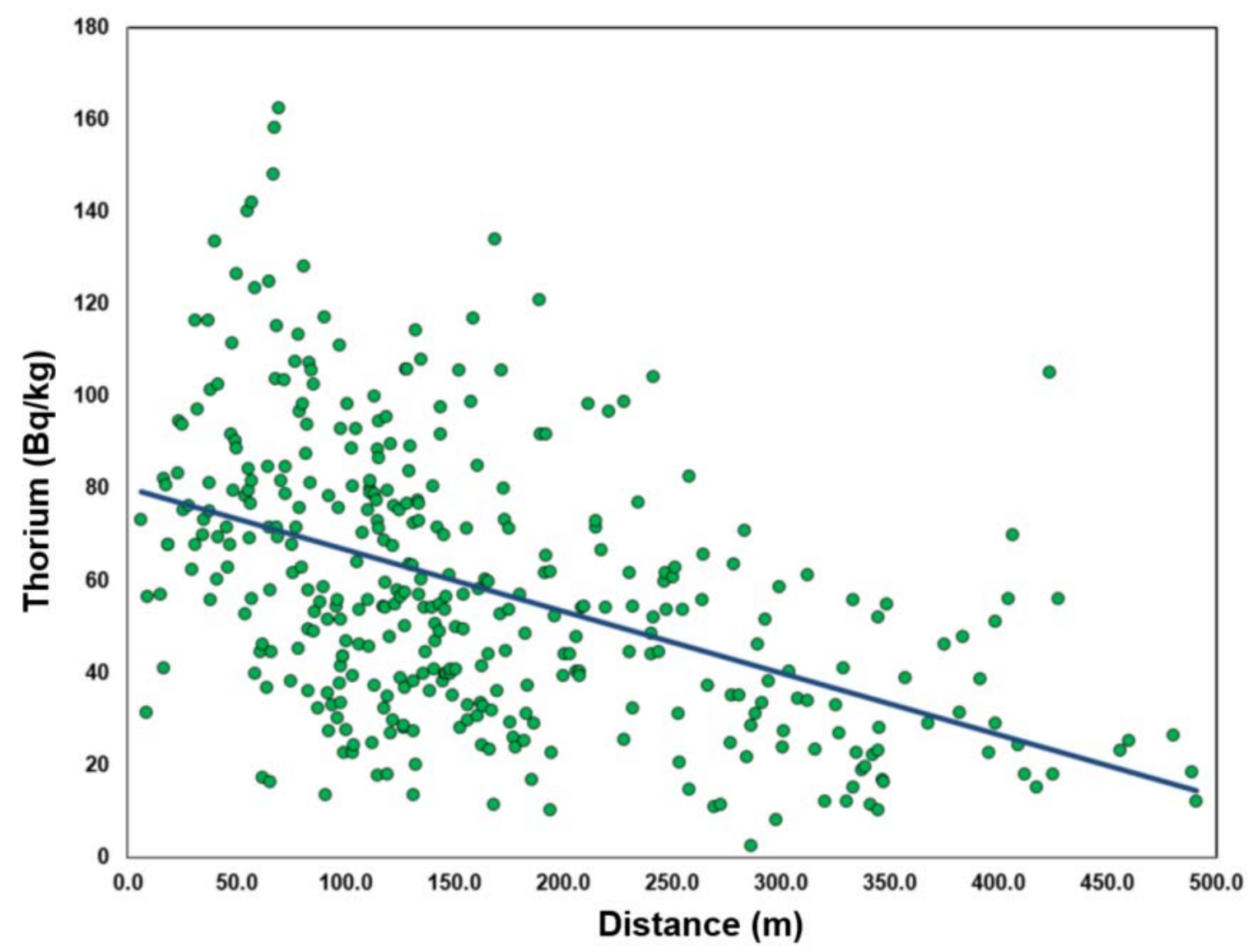

Figure 6. A graph of thorium concentration to the distance. The distance were determined between the point where the concentration was measured and the centre of the processing plant. The blue line shows a trend line that demonstrates the decrease of concentration with distance.

The concentrations of thorium are plotted as a function of the radium concentrations in Figure 7. A second order polynomial trend line of the relationship between these concentrations is also illustrated on the graph. It is evident from the trend line that the $\mathrm{Th} / \mathrm{Ra}$ ratio decreases as the radium concentrations increases. The overall radium concentrations are also much higher than the thorium concentrations, contrary to general natural trends in soil. These elevated radium levels as well as the non-linear relationship between thorium and radium at high concentrations typically indicate that the residual material were refinement. The phosphate refinement consequently technologically enhances the high concentrations of naturally occurring radium and this resulted in high levels of radium contamination in the processing plant. 


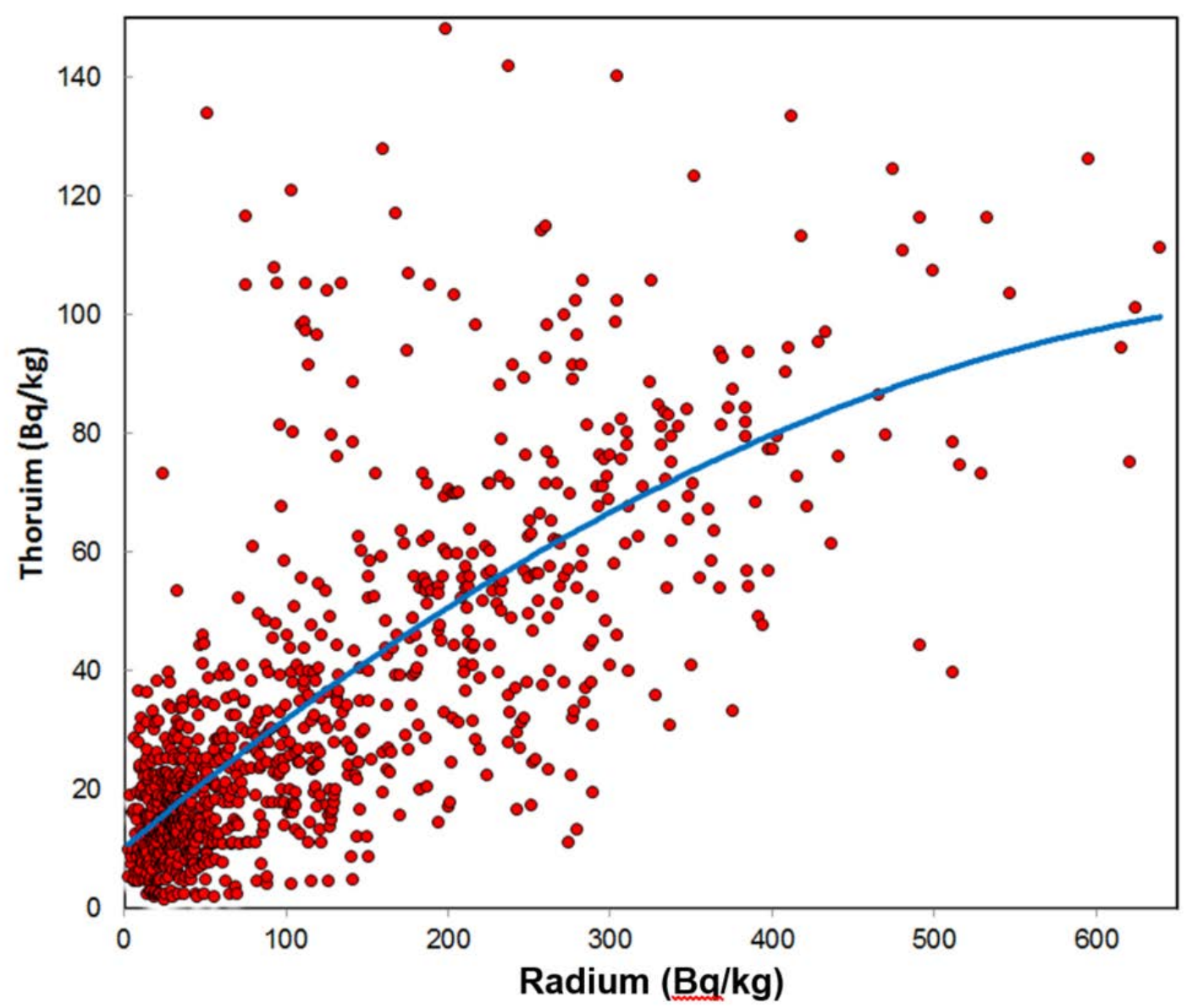

Figure 7. A graph of the thorium to radium concentrations of all the points that were measured at the phosphate mine. The blue line shows a second order polynomial trend line of the relationship.

High levels of potassium were associated with areas that were covered by concrete and this may be as a result of the high concentrations of natural potassium that are prevalent in gravel. Gravel (crushed granite) is a key ingredient of concrete. The highest potassium concentrations of 898 $\mathrm{Bq} / \mathrm{kg}$ were measured on the concrete floor of the indoor storage area. The potassium concentrations were incorporated in the calculations of the annual effective dose rate.

The annual effective dose rate for the processing plant of the mine was calculated by adding the three naturally occurring nuclides according to the functions in equations (18) and (19). The exposure level at each point is illustrated in Figure 8 and it is evident that these levels mainly coincide with the radium concentrations, due to the dominance of radium over thorium and potassium on the site. The annual effective dose decrease as the distance from the central part of the plant increases and this is demonstrated in Figure 9. The point with the maximum annual effective dose rate was estimated at $0.45 \mathrm{mSv} / \mathrm{y}$ and found to be situated between the mills and the phosphate storage area of the processing plant (Figure 8). This area is characterised by sandy soil. The phosphate with the associated radium was probably transported and stored on this surface and spillages filtered into the top soil. This indicates that the contaminated area probably had no surface cover or lining during the mining project. The method that was used in this study can only determine radionuclide concentrations up to a depth of $0.5 \mathrm{~m}$ and it was therefore impossible to estimate to what depth the radioactive contamination extended. 


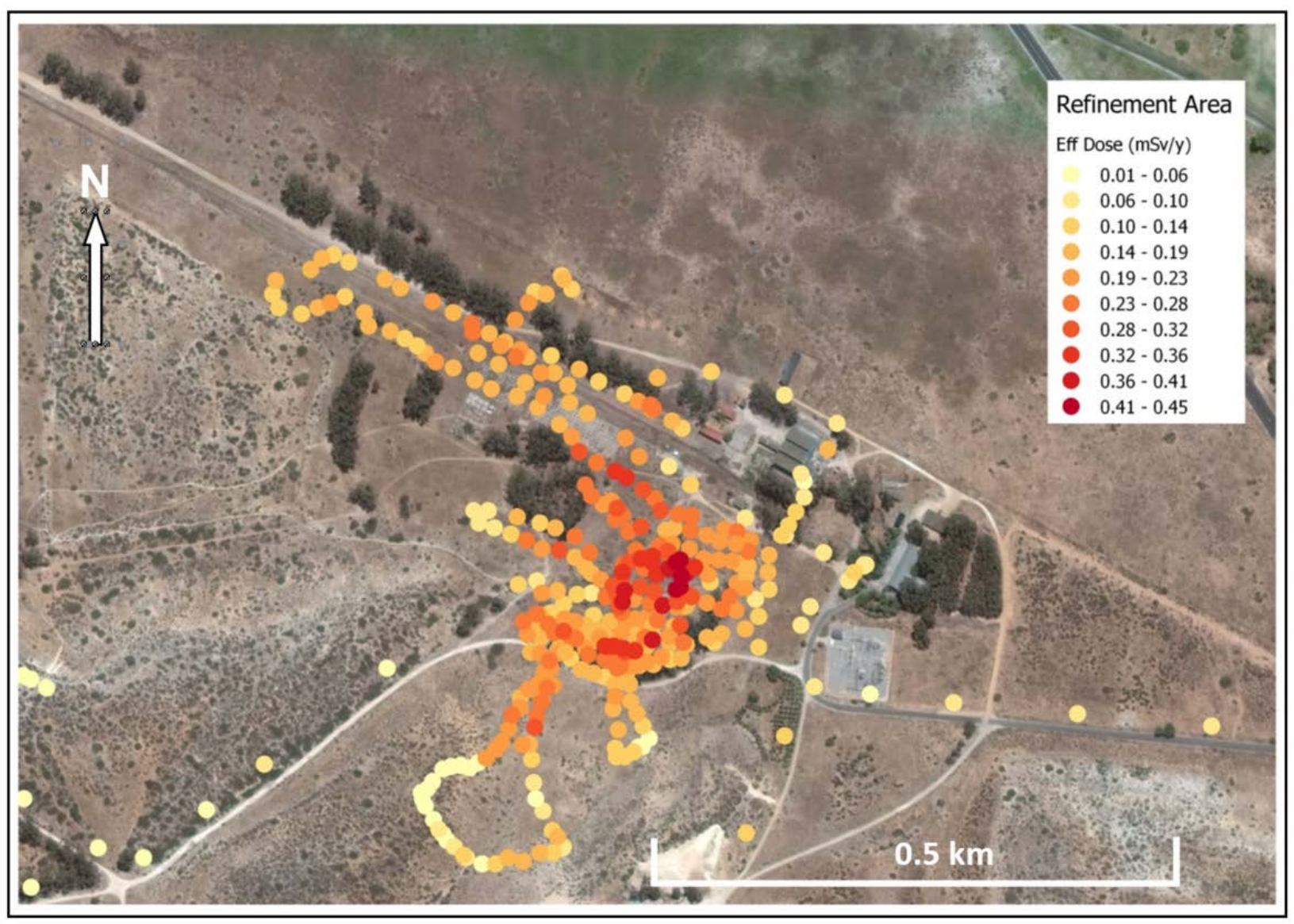

Figure 8. A Google Earth image with a colour-graded overlay indicating the annual effective dose rate in the processing plant of the spent phosphate mine. 


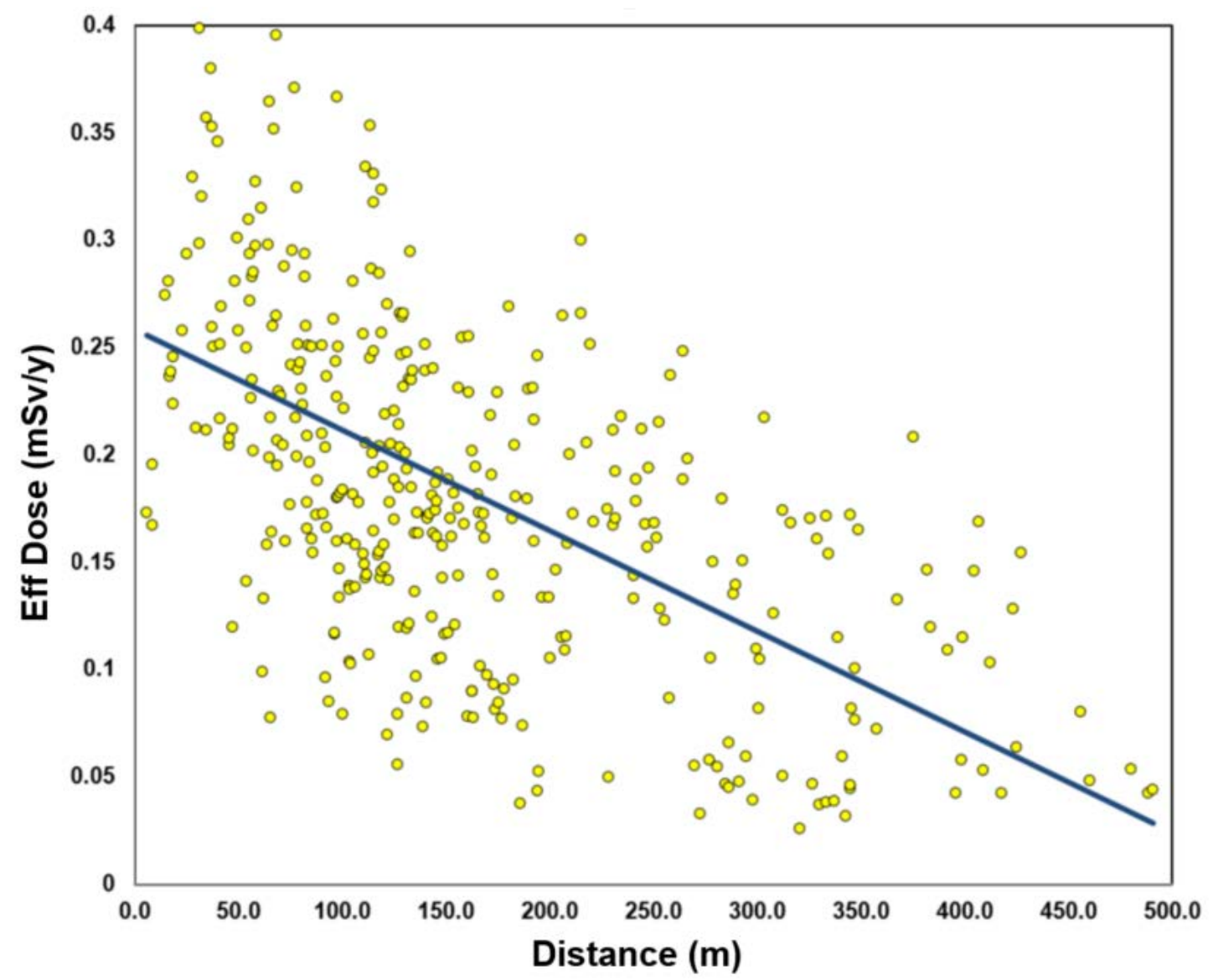

Figure 9. A graph of annual effective dose to the distance. The distance were determined between the point where the annual effective dose was determined and the centre of the processing plant.

The blue line shows a trend line that demonstrates the decrease of annual effective dose with distance.

A more comprehensive estimation of the effective dose was needed in order to map the complete area of the processing plant. The measured points therefore needed to be interpolated to obtain values for the areas of the processing plant that were not subjected to in situ measurements. This was done by constructing a heat map of the effective dose rates and overlying that on a Google Earth image of the processing plant (Figure 10). It is evident that the area with the highest exposure is around the centre of the processing plant and also on the railroad tracks that lead of to the northwest. This again emphasizes the spillages that took place in the final stages of phosphate processing as well as when railcars were loaded. However, the cumulative estimated effective dose rates are still below the acceptable level of $1 \mathrm{mSv} / \mathrm{y}$ as prescribed by UNSCEAR [3]. Having said that, the biological impact due to chemical pollution in the area was not determined and this may pose risks to the natural environment. 


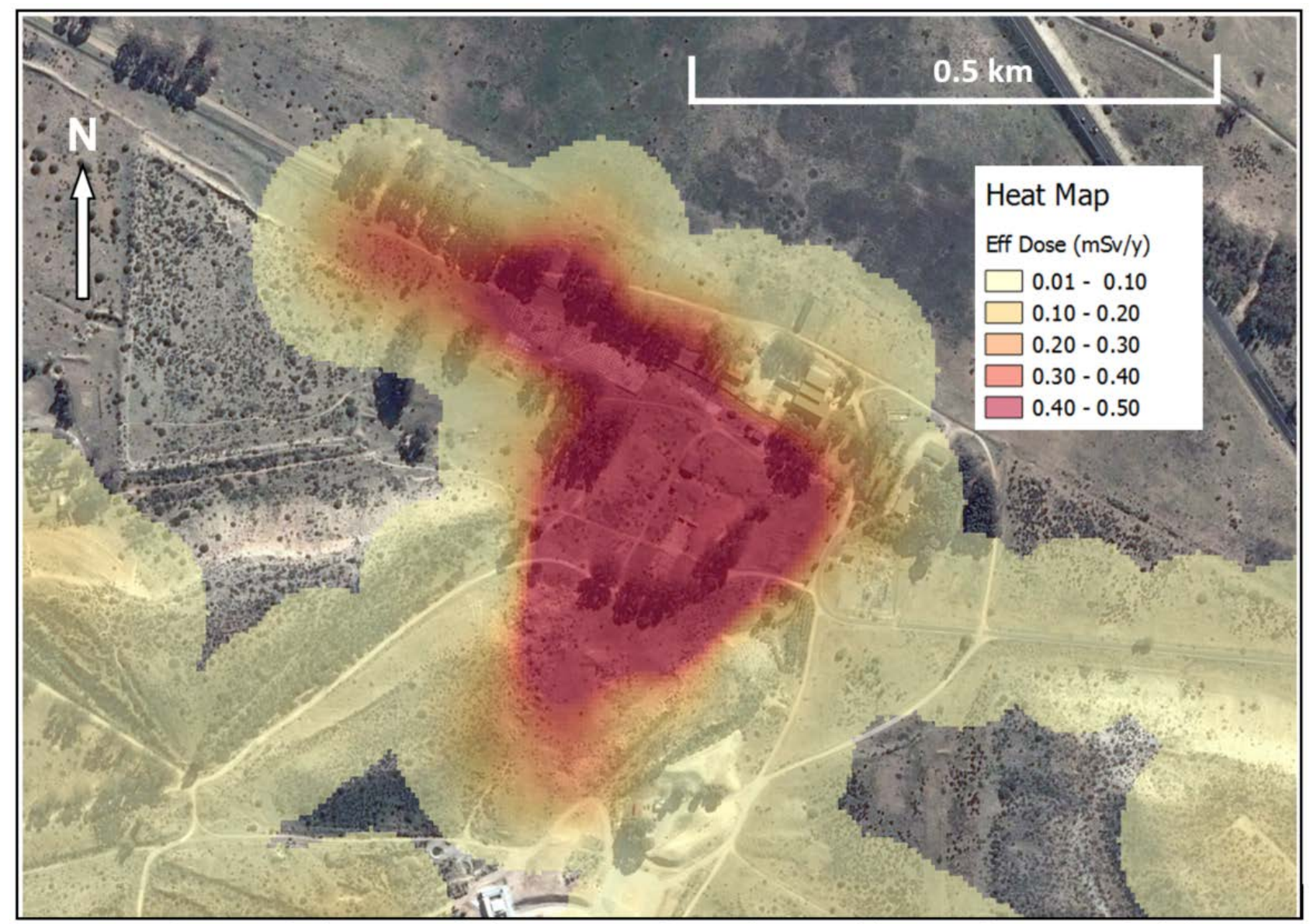

Figure 10. A Google Earth image of the processing plant with a colour-graded heat map of the effective dose as overlay.

It is evident from the radium concentrations that the technological enhancement of naturally occurring radioactive materials poses risks of contamination when refinement of phosphate takes place. Spillages should therefore be prevented as far as possible and all the technological enhanced material should be stored and disposed of in a responsible manner. Dedicated and prepared waste dump sites should also be earmarked for disposal of such radioactive material. The waste should be physically confined to stop meteorological processes from spreading it. The dump sites should also be lined to prevent contamination of ground water and soil. If this is not done, clean-up during decommissioning of such a mine will be difficult and costly.

It is further important that all refinement is done on covered surfaces in order to prevent the mixing of radionuclide with the top soil. It is vital to prevent radioactive spillages as far as possible as cleaning of spillages are problematic. The implementation of these measures is important to prevent long-term chemical and radioactive pollution when mining uranium bearing ores. Special care should be taken to prevent contamination of water bodies with radium (uranium) bearing material as this can lead to serious health risks [21]. 


\section{Conclusions}

Phosphate mining and refinement is characterized by high levels of radioactive uranium and its accompanying daughter nuclides, like radium. The processing plant of a spent phosphate mine on the west coast of South Africa was intensively surveyed and radionuclide concentrations were analyzed and mapped. A mobile gamma ray survey instrument named the GISPI was utilized for these measurements. High concentrations of radium were found in the old mill and storage areas of the plant. A corridor along which the phosphate was transported to the railroad also demonstrated elevated radium concentrations that most probably emanates from spillages.

A non-linear trend was found in the Th/Ra ratio and this probably resulted from the refinement process in which selective technological enhancement of naturally occurring radioactive materials occurred. The sample points with the highest concentrations of thorium did however not coincide with those of radium. These results illustrate that radium associates with phosphate during refinement and consequently contaminate the environment where spillages of the refined phosphate occur. Measures to limit refined phosphate spillages are therefore essential in order to ensure that soil and underground water are not contaminated.

The effective dose rates were also estimated based on the measured nuclide concentrations and the effective dose rates correlated with high radium concentrations. It is evident that radioactive contamination occurred at the final phases of refinement on the possessing plant of this mine. The study indicates that long-term pollution may occur if preventative measures are not put into place when mining uranium bearing ores. Additional measurements are planned to determine the depth to which the radium has distributed in the soil at the processing plant.

\section{Acknowledgements}

The author would like to thank the management and trustees of the West Coast Fossil Park for their support in this study as well as the National Research Fund of South Africa for the funds that they provided for this research.

\section{References}

1. A.E.M. Khatera, R.H. Higgya, M. Pimpl 2001. Radiological impacts of natural radioactivity in Abu-Tartor phosphate deposits, Egypt, Journal of Environmental Radioactivity, 55, 255-267.

2. S.K. Sahu, P.Y. Ajmal, R.C. Bhangare, R.C. Tiwari, G.G. Pandit, 2014. Natural radioactivity assessment of a phosphate fertilizer plant area. Journal of Radiation Research and Applied Science, 7, 123-128.

3. UNSCEAR. 2000. United Nations Scientific Committee on the Effect of Atomic Radiation. Exposure from natural radiation sources. New York: United Nations.

4. H. Vandenhove, J.V. i Batlle, L. Sweeck, 2015. Potential radiological impact of the phosphate industry on wildlife. Journal of Environmental Radioactivity, 141, 14-23.

5. L. Sciscio, F.H. Neumann, D. Roberts, H. Tsikos, L. Scott, M. Bamford, 2013. Fluctuations in Miocene climate and sea levels along the south western South African coast: inferences from biogeochemistry, palynology and sedimentology. Palaeontologica Africana, 48: 2-18. 
6. West Coast Fossil Park 2010, Langebaanweg, South Africa, viewed 6 September 2018, $<$ http://www.fossilpark.org.za/>.

7. J. Bezuidenhout, 2015. The Testing and Implementation of a Transportable and Robust Radio-element Mapping System. South African Journal Science, Vol 111, No 9/10.

8. J. Bezuidenhout, 2015. In situ gamma ray measurements of radionuclides at a disused phosphate mine on the West Coast of South Africa. Journal of Environmental Radioactivity, 150.

9. FLIP Systems Inc. 2018, 9 Townsend West, Nashua, USA, viewed 6 September 2018, $<$ http://www.flir.com/>.

10. Trimble Inc. 2018, 935 Stewart Drive, Sunnyvale, California, viewed 6 September 2018, $<$ http://www.trimble.com>.

11. T. McCay, T.L. Harley, P.L. Younger, D.C.W. Sanderson, A.J. Cresswell, 2014. Gamma-ray Spectrometry in Geothermal Exploration: State of the Art Techniques Alistair. Energies, 7(8), 4757-4780.

12. L. Rybach, 1971. Radiometric techniques. In: Wainerdi, R.E., Uken E.A., (Eds.). Modern Methods of Geochemical Analysis. Plenum Press, New York.

13. L. Rybach, 1988. Determination of the heat production rate. In: Haenel, R., Rybach, L., Stegena, L., (Eds.). Handbook of Terrestrial Heat-Flow Density Determination. Kluwer Academic Publishers, Dordrecht.

14. E.O. Agbalagba, G.O. Avwiri, Y.E. Chad-Umoreh, 2012. $\gamma$-Spectroscopy measurement of natural radioactivity and assessment of radiation hazard indices in soil samples from oil fields environment of Delta State, Nigeria. Journal of Environmental Radioactivity, 109. 64-70.

15. P. Chiozzi, P. De Felice, A. Fazio, V. Pasquale, M. Verdoy, 2000. Laboratory application of NaI(Tl) $\gamma$ ray spectrometry to studies of natural radioactivity in geophysics. Applied Radiation and Isotopes, 53, $127-132$.

16. B. Corner, P.D. Toens, D.J, Richards, D. Van As, C.M. Vleggaar, 1979. The Pelindaba facilities for calibrating radiometric field instruments. Publication of Atomic Energy Board, No. PEL-268, Pretoria.

17. National Institute of Standards and Technology 2018, 100 Bureau Drive, Gaithersburg, USA, viewed 6 September 2018, <http://www.nist.gov/pml/data/comp.cfm/>.

18. P.S.C. Silva, B.P. Mazzilli, D.I.T. Fávaro, 2006. Environmental contamination by technologically enhanced naturally occurring radioactive material - TENORM: A case study of phosphogypsum. Journal of Radioanalytical and Nuclear Chemistry, Vol 269, Issue 3, 739-745.

19. A.G.E. Abbady, 2010. Evaluation of heat generation by radioactive decay of sedimentary rocks in Eastern Desert and Nile Valley, Egypt. Applied Radiation and Isotopes, 68, 2020-2024.

20. M.L. Montes, R.C. Mercader, M.A. Taylor, J. Runco, J. Desimoni, 2012. Assessment of natural radioactivity levels and their relationship with soil characteristics in undisturbed soils of the northeast of Buenos Aires province, Argentina. Journal of Environmental Radioactivity, 105, 30-39.

21. F. Winde, 2009. Uranium Pollution Of Water Resources In Mined-Out And Active Goldfields Of South Africa - A Case Study In The Wonderfonteinspruit Catchment On Extent And Sources Of UContamination And Associated Health Risks. Abstracts of the International Mine Water Conference 2009. Proceedings ISBN: 978-0-9802623-5-3, Pretoria, South Africa. 